\title{
Inpatient hospital performance is associated with post-discharge sepsis mortality
}

\author{
Nicholas M. Mohr ${ }^{1,2^{*}}$, Alexis M. Zebrowski ${ }^{3}$, David F. Gaieski ${ }^{3}$, David G. Buckler ${ }^{3}$ (D) and Brendan G. Carr ${ }^{4}$
}

\begin{abstract}
Background: Post-discharge deaths are common in patients hospitalized for sepsis, but the drivers of post-discharge deaths are unclear. The objective of this study was to test the hypothesis that hospitals with high risk-adjusted inpatient sepsis mortality also have high post-discharge mortality, readmissions, and discharge to nursing homes.

Methods: Retrospective cohort study of age-qualifying Medicare beneficiaries with sepsis hospitalization between January 2013 and December 2014. Hospital survivors were followed for 180-days post-discharge, and mortality, readmissions, and new admission to skilled nursing facility were measured. Inpatient hospital-specific sepsis risk-adjusted mortality ratio (observed: expected) was the primary exposure.

Results: A total of 830,721 patients in the cohort were hospitalized for sepsis, with inpatient mortality of $20 \%$ and 90-day mortality of $48 \%$. Higher hospital-specific sepsis risk-adjusted mortality was associated with increased 90 -day post-discharge mortality (aOR 1.03 per each 0.1 increase in hospital inpatient O:E ratio, 95\% Cl 1.03-1.04). Higher inpatient risk adjusted mortality was also associated with increased probability of being discharged to a nursing facility (aOR 1.03, 95\% Cl 1.02-1.03) and 90-day readmissions (aOR 1.03, 95\% Cl 1.02-1.03).

Conclusions: Hospitals with the highest risk-adjusted sepsis inpatient mortality also have higher post-discharge mortality and increased readmissions, suggesting that post-discharge complications are a modifiable risk that may be affected during inpatient care. Future work will seek to elucidate inpatient and healthcare practices that can reduce sepsis post-discharge complications.
\end{abstract}

Keywords: Sepsis, Quality of health care, Patient discharge, Patient readmission

\section{Background}

Sepsis is a life-threatening condition that affects 1.7 million Americans annually, with an in-hospital mortality of $16 \%$ [1]. Costing over $\$ 60$ billion each year, sepsis is the most expensive acute medical condition for which Medicare reimburses hospitals [2]. Early treatment has been shown to improve survival to hospital discharge $[1,3,4]$, but sepsis case-fatality continues to vary significantly by hospital (41\% for highest-mortality decile of hospitals vs. $29 \%$ for lowest-mortality decile, $p<0.001$ ) [5].

\footnotetext{
*Correspondence: nicholas-mohr@uiowa.edu

${ }^{1}$ Department of Emergency Medicine, University of lowa Carver College of Medicine, 200 Hawkins Drive, 1008 RCP, lowa City, IA 52242, USA

Full list of author information is available at the end of the article
}

The burden of sepsis continues beyond hospital discharge. Many sepsis survivors have persistent neurocognitive deficits, neuromuscular weakness, symptoms of depression and post-traumatic stress disorder, and poor quality of life [6-10]. Readmissions after discharge are common (21\% within 30 days) [11], and sepsis survivors have increased post-discharge mortality [12-14]. Postdischarge deaths have been associated with premorbid health status and hospital factors $[15,16]$, but it is unclear whether these factors are modifiable, and whether hospital care can alter the post-discharge course.

The objective of this study was to determine the relationship between quality of hospital care (measured by hospital-specific inpatient adjusted sepsis survival) and post-discharge outcomes, including original author(s) and the source, provide a link to the Creative Commons licence, and indicate if changes were made. The images or other third party material in this article are included in the article's Creative Commons licence, unless indicated otherwise in a credit line to the material. If material is not included in the article's Creative Commons licence and your intended use is not permitted by statutory regulation or exceeds the permitted use, you will need to obtain permission directly from the copyright holder. To view a copy of this licence, visit http://creativecommons.org/licenses/by/4.0/. The Creative Commons Public Domain Dedication waiver (http://creativeco mmons.org/publicdomain/zero/1.0/) applies to the data made available in this article, unless otherwise stated in a credit line to the data. 
mortality, readmissions, and skilled nursing facility discharge (Fig. 1). We postulate that hospitals that provide higher quality care have improved sepsis riskadjusted inpatient mortality and that this quality leads to improved post-discharge mortality in those who survive hospitalization. This analysis differs from prior work, in that we are evaluating a primary exposure of hospital performance (a more direct measure of hospital quality) rather than administrative or epidemiologic factors than may be related with quality indirectly, and our outcome includes only those who survive hospitalization [15-18]. Such a relationship would suggest that the impact of inpatient sepsis therapies may extend beyond hospital discharge, and that early treatment elements may change long-term immunity, organ function, and debility.

\section{Methods}

\section{Study design, setting, and participants}

This analysis was a retrospective cohort study of agequalifying Medicare beneficiaries with an emergency department (ED)-based hospitalization in a U.S. hospital for sepsis or septic shock between January 1, 2013 and December 31, 2014. Hospital encounters were identified using the Outpatient and Medicare Provider Analysis and Review (MedPAR) research identifiable files from the Centers for Medicare and Medicaid Services (CMS) administrative claims data, while patient demographic information and dates of death were obtained from the Medicare Beneficiary Summary File and Vital Status records. All cases were followed for 6 months after hospital admission, with deaths from any cause captured through June 30, 2015 for the last-enrolling patients, and readmissions for any cause censored on December 31, 2014 due to the years of Outpatient and MedPAR data available. In-hospital mortality was estimated using data from January 1, 2013 through December 31, 2014, and these mortality estimates were used for calculating observed-to-expected (O:E) mortality ratios for inclusion in subsequent explanatory models. Only hospitals with at least 200 cases during the 2-year period were included in the analysis to allow for more stable O:E ratio estimates. This study was approved by the local institutional review board (IRB) and is reported using the STrengthening the Reporting of OBservational studies in Epidemiology (STROBE) statement [20].

\section{Definitions}

Severe sepsis or septic shock was defined according to International Classification of Diseases, 9th edition, Clinical Modification (ICD-9-CM) diagnosis codes for septicemia with an additional diagnosis for organ dysfunction, as previously reported [21-23]. Rural residence was defined based on the county of residence, and was classified according to the 2013 Rural-Urban Continuum Codes (RUCC) published by the U.S. Department of Agriculture [24]. Comorbidities were defined using the Elixhauser method, which identifies a set of 30 comorbid conditions from administrative data associated with increased mortality, length-of-stay, and charges [25]. Index hospital was the first hospital where a patient was seen for a given sepsis episode, while final hospital was the last hospital where a patient was seen (to account for patients transferred between hospitals for their care).

\section{Exposures \\ Hospital-specific mortality}

The primary exposure was hospital-specific sepsis mortality. Hospital-specific sepsis mortality was reported as an O:E mortality ratio based strictly on in-hospital mortality for the final hospital in which a patient was treated, calculated for the study period 2013-2014. A multivariable logistic regression model was constructed with an outcome of in-hospital mortality and a priori-defined patient-level predictors, including age, race, sex, comorbidities, infection source, organ dysfunction, skilled nursing facility residence prior to admission, community

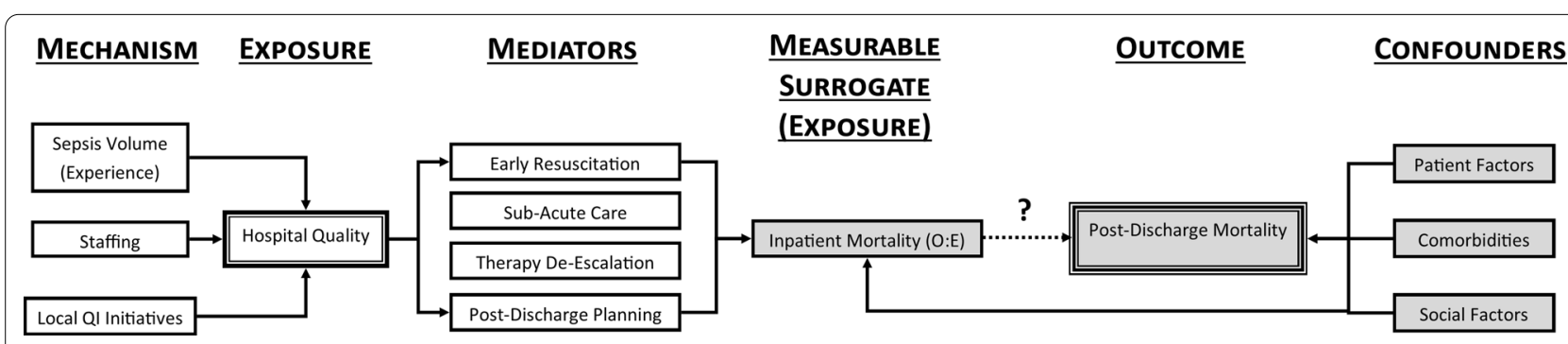

Fig. 1 Proposed causal diagram for the hypothesized relationship between hospital-specific observed:expected (O:E) mortality ratio and post-discharge mortality. Shaded boxes indicate parameters that are measurable (non-shaded boxes are unmeasured). In our primary analysis, we are using inpatient O:E mortality as a surrogate approximation of hospital quality. The purpose of this analysis is to understand to what degree post-discharge mortality may be modifiable based on hospital-level care 
factors (percent Black, percent Hispanic, percent with high school degree or higher, percent below poverty line), ICU services in hospital, and teaching hospital. All variables were selected based on theory and the proposed relationship with exposures and outcomes, and the same adjustment variables were used for all models $[5,17,26]$. All continuous variables were modeled in categories, and interactions were tested. The predicted probability of mortality was generated for each case in the data set, then the sum of observed in-hospital mortality and predicted in-hospital mortality for each facility was calculated. The ratio of the observed mortality to the predicted mortality was the O:E ratio and was the primary predictor in this analysis.

\section{Primary and secondary outcomes}

\section{Primary outcome}

The primary outcome was 90-day post-discharge mortality, measured from the date of hospital discharge among patients who survived their initial sepsis hospitalization. The primary analysis used a hierarchical logistic regression model clustered on the final hospital with the primary exposure of hospital-specific O:E mortality ratio and other potential patient and system-oriented confounders. Interactions were tested and all continuous variables were coded into categorical groups. Covariates for the model were selected based on prior data and possible confounders in patient-level, facility-level, and community-level variables.

\section{Secondary analyses}

Secondary analytic models were developed to measure mortality at 30 days, 60 days, and 180 days post-discharge. A sensitivity analysis was performed using the hospital O:E ratio for the index hospital, rather than the final hospital, to determine if assigning ownership to the first hospital changed the association with post-discharge outcomes. Multivariable models were built similarly to measure the association between hospital-specific predictors on hospital discharge to skilled nursing facility (only among cases that did not reside in a skilled nursing facility at the time of index admission) and readmission within the first 90-days after discharge.

\section{Sensitivity analysis \\ Survival models}

An alternative approach was planned a priori to function as a sensitivity analysis (if the impact of hospital mortality on post-discharge mortality appeared preserved across time, supporting the proportional hazards assumption): a Cox proportional hazards model was developed with the same set of covariates and an outcome of time-to-death, among patients who survived the initial hospitalization.
A second proportional hazards model was built for timeto-readmission among hospital survivors.

\section{Unobserved confounder}

An " $E$-value" was calculated to determine the minimum strength of association required with both the predictor and the outcome, for an unobserved confounder to render the coefficient of our primary exposure null. In this way, we estimated how significant an unobserved variable would have to be for our results to be attributable to confounding bias alone. To interpret this value, the reader might conclude that a confounding variable not included in the model would have to have an odds ratio of at least this value for our findings to be a result of confounding alone.

\section{Analysis}

For all multivariable models, continuous predictor variables were categorized to avoid the linearity assumption, interactions were tested for significance, and variables were screened for multicollinearity. All analyses are done using complete case analysis, and goodness of fit was assessed using area under the curve (AUC) of the final model. All statistical tests were considered significant for $p<0.05$ using two-tailed tests, and all analysis was conducted using Stata v.15.1. (StataCorp LLC, College Station, Texas).

\section{Results}

A total of 830,720 age-qualifying Medicare beneficiaries were hospitalized for sepsis between 2013 and 2014 (Fig. 2). We excluded 123,807 admissions in 1922 lowvolume hospitals with fewer than 200 cases during the sample period. Most patients (68\%) were hospitalized with either a respiratory or urinary infection source, $14 \%$ had a co-existing malignancy, and $9 \%$ were admitted from a skilled nursing facility (Table 1). Of all cases, $1 \%$ were transferred between hospitals. In-hospital mortality was $20 \%(n=167,854)$, with 30 -day, 90 -day, and 180-day cumulative mortality of $35 \%(n=291,708), 43 \%$ $(n=353,147)$, and $48 \%(n=398,914)$, respectfully. Of sepsis discharges, $37 \%(n=247,045)$ were readmitted to a hospital within 180 days, with the median time to readmission approximately 32 days (IQR $12-73$ days).

\section{Association between in-hospital mortality and post-discharge mortality}

The median index hospital O:E ratio was 1.00 (IQR 0.831.17), with 1585 hospitals reporting at least 200 cases over the 2-year period. O:E ratios ranged from 0.29 to 2.20 (IQR 0.83-1.17, Additional file 1: Fig. S1, Additional file 2: Table S1). In univariable modeling, increasing hospital-specific O:E ratios were associated with increased 


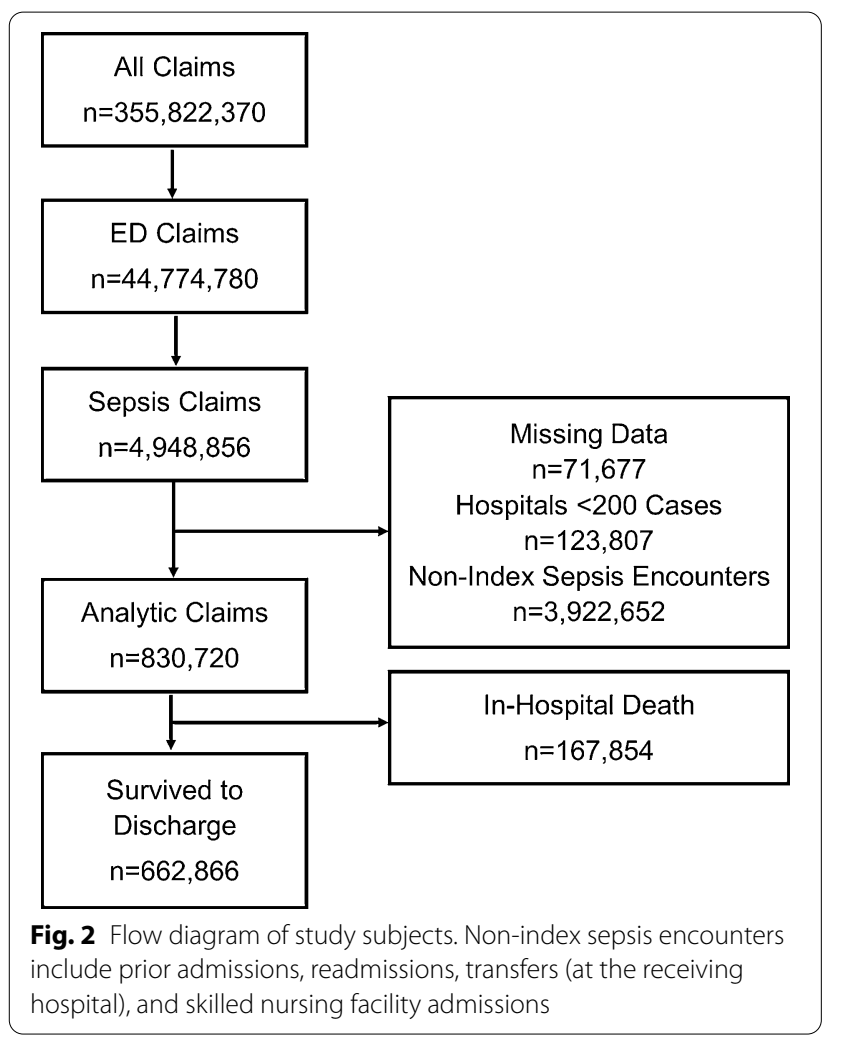

post-discharge mortality at 90-days (unadjusted OR 1.08 for each 0.1 increase in hospital-specific O:E ratio, 95\% CI 1.08-1.08). Controlling for potentially confounding patient-, facility-, and community-level covariates, the adjusted odds ratio showed a strong association between hospital O:E ratios and mortality (aOR 1.03 for each 0.1 increase in hospital-specific O:E ratio, 95\% CI 1.03-1.04). The magnitude of effect was unchanged for mortality from 30 to 180 days (Fig. 3, Additional file 3: Table S2).

\section{Secondary outcomes}

No differences were seen in the association between index hospital O:E and 90-day post-discharge mortality compared with the use of final hospital in the primary models (aOR 1.03, 1.03-1.04). Of the 610,874 patients that did not live in a nursing facility prior to their index sepsis admission and who survived to discharge, 25\% $(n=153,378)$ were discharge to a SNF. Using a multivariable model similar to the primary model, patients from hospitals with the highest O:E ratios had an increased odds of being discharged to a skilled nursing facility (aOR 1.03 per 0.1 increase in O:E mortality ratio for final hospital, 95\% CI 1.02-1.03). Similarly, patients from hospitals with the highest risk-adjusted mortality also had increased probability of 90-day readmissions (aOR 1.03 per 0.1 increase in O:E for final hospital, 95\%
CI 1.02-1.03). By 180-days after discharge, the adjusted odds of readmission had decreased to 1.02 per 0.1 increase in O:E (95\% CI 1.02-1.03).

\section{Survival analysis}

As a sensitivity analysis, a Cox proportional hazards model was used to measure the time to death, accounting for all the covariates from the logistic regression models and the hospital O:E ratio (Fig. 3). The hazard ratio for post-discharge mortality was higher in patients treated in a hospital with a higher O:E ratio (aHR 1.02 per 0.1 increase in O:E for final hospital, 95\% CI 1.02-1.03). A "dose-response" relationship was seen between hospital $\mathrm{O}: \mathrm{E}$ and mortality with lower hazard for post-discharge mortality in the lower categories of hospital O:E (reference group < 0.75 ; 0.75-1.00: aHR 1.01, 95\% CI 1.00-1.01; 1.00-1.25: aHR 1.01, 95\% CI 1.01-1.01; > 1.25: aHR 1.02, 95\% CI 1.01-1.02). A Cox proportional hazards model was also used to assess time to readmission. In adjusted models, higher hospital O:E ratios were associated with increased readmissions (aHR: 1.02 per 0.1 increase in O:E for index hospital, 95\% CI 1.02-1.03). For hospitals with an O:E ratio $>1.25$, median time to readmission within the first 180 days after discharge was 30 days (IQR 11-69) compared with 34 days in hospitals with an $\mathrm{O}: \mathrm{E}<0.75$ (IQR 13-76).

In our sensitivity analysis to measure the theoretical magnitude of an unobserved confounder ( $E$-value), the magnitude of bias introduced by an unmeasured variable must have an odds of at least 2.05 (lower 95\% CI 1.88). A moderately strong predictor of both hospital O:E and death at 90 days would be required to result in null findings (similar in magnitude to premorbid cancer diagnosis or nursing home residence). It seems unlikely that an unobserved variable predicting mortality with a magnitude equal to nursing home residence exists.

\section{Discussion}

The relationship between sepsis and post-discharge mortality has been well established [12-14, 27], but whether post-discharge mortality has modifiable treatment-related risks remained unclear. This question has been challenging to answer, since the specific biological mechanisms by which post-sepsis mortality is elevated have not been well elucidated. Mechanistic data suggest that sepsis survivors remain immune suppressed [28, 29], have increased rates of atherosclerosis [13, 30], and that epigenetic regulation may play a role in modulating these effects [31]. The question that mechanistic studies have not answered, however, is whether improved inpatient care can attenuate the impact on late post-discharge mortality. By analyzing variation between U.S. hospitals, our data suggests that it may. 
Table 1 Baseline characteristics of the study population

\begin{tabular}{|c|c|c|}
\hline \multirow[t]{3}{*}{ Characteristic } & \multicolumn{2}{|l|}{ Descriptive statistics } \\
\hline & All cases $(n=830,720)$ & $\begin{array}{l}\text { Survived } \\
\text { to discharge } \\
(n=662,866)\end{array}$ \\
\hline & $n(\%)$ & $n(\%)$ \\
\hline \multicolumn{3}{|l|}{ Patient characteristics } \\
\hline \multicolumn{3}{|l|}{ Sex } \\
\hline Male & $393,852(47.4)$ & $314,824(47.5)$ \\
\hline Female & $436,868(52.6)$ & $348,042(52.5)$ \\
\hline \multicolumn{3}{|l|}{ Race } \\
\hline White & $641,526(77.2)$ & $512,243(77.3)$ \\
\hline Black & $101,581(12.2)$ & $79,308(12.0)$ \\
\hline Other & $87,613(10.6)$ & $71,315(10.8)$ \\
\hline \multicolumn{3}{|l|}{ Age } \\
\hline $65-74$ years & $274,021(33.0)$ & $225,032(33.9)$ \\
\hline $75-84$ years & $303,933(36.6)$ & $242,410(36.6)$ \\
\hline $85+$ years & $252,766(30.4)$ & $195,424(29.5)$ \\
\hline \multicolumn{3}{|c|}{ Urbanicity of residence (by RUCC code) } \\
\hline Urban (metro counties) & $740,872(89.2)$ & $590,784(89.1)$ \\
\hline Rural (nonmetro counties) & $89,377(10.8)$ & $71,715(10.8)$ \\
\hline Other/unknown & $471(0.1)$ & $367(0.1)$ \\
\hline \multicolumn{3}{|l|}{ Cancer diagnosis } \\
\hline None & $715,653(86.2)$ & $580,536(87.6)$ \\
\hline Metastatic solid tumor & $10,656(1.3)$ & $7,208(1.1)$ \\
\hline Non-metastatic solid tumor & $72,133(8.7)$ & $51,807(7.8)$ \\
\hline Hematologic malignancy & $32,278(3.9)$ & $23,315(3.5)$ \\
\hline \multicolumn{3}{|l|}{ Infection source } \\
\hline Urinary tract & $338,046(40.7)$ & $288,389(43.5)$ \\
\hline Pneumonia & $225,647(27.2)$ & $171,908(25.9)$ \\
\hline Abdominal & $33,433(4.0)$ & $24,135(3.6)$ \\
\hline Bloodstream & $26,217(3.2)$ & $22,148(3.3)$ \\
\hline Cellulitis & $24,288(2.9)$ & $21,407(3.2)$ \\
\hline Bone & $17,909(2.2)$ & $15,247(2.3)$ \\
\hline Surgical & $10,960(1.3)$ & $9329(1.4)$ \\
\hline Ear, nose, throat & $1240(0.2)$ & $1130(0.2)$ \\
\hline Meningitis & $1051(0.1)$ & $832(0.1)$ \\
\hline Gastrointestinal & $794(0.1)$ & $755(0.1)$ \\
\hline Other/unknown & $151,135(18.2)$ & $107,586(16.2)$ \\
\hline \multicolumn{3}{|l|}{ Organ dysfunction } \\
\hline Renal & $250,655(30.2)$ & $212,506(32.1)$ \\
\hline Neurologic & $227,220(27.4)$ & $177,610(26.8)$ \\
\hline Metabolic & $145,086(17.5)$ & $101,214(15.3)$ \\
\hline Hematologic & $73,996(8.9)$ & $61,618(9.3)$ \\
\hline Cardiac & $50,414(6.1)$ & $39,498(6.0)$ \\
\hline Respiratory & $41,985(5.1)$ & $35,072(5.3)$ \\
\hline Hepatic & $8396(1.0)$ & $5525(0.8)$ \\
\hline Other/unknown & $32,968(4.0)$ & $29,823(4.5)$ \\
\hline \multicolumn{3}{|c|}{ Admission from skilled nursing facility } \\
\hline No & 759,098 (91.4) & $618,575(93.3)$ \\
\hline Yes & $71,622(8.6)$ & $50,291(7.6)$ \\
\hline
\end{tabular}


Table 1 (continued)

\begin{tabular}{|c|c|c|}
\hline \multirow[t]{3}{*}{ Characteristic } & \multicolumn{2}{|l|}{ Descriptive statistics } \\
\hline & All cases $(n=830,720)$ & $\begin{array}{l}\text { Survived } \\
\text { to discharge } \\
(n=662,866)\end{array}$ \\
\hline & $n(\%)$ & $n(\%)$ \\
\hline \multicolumn{3}{|l|}{ Hospital characteristics } \\
\hline \multicolumn{3}{|l|}{ ICU services available } \\
\hline No & $10,409(1.3)$ & $8,633(1.3)$ \\
\hline Yes & $736,934(88.7)$ & $588,136(88.7)$ \\
\hline Not reported/unknown & $83,377(10.0)$ & $66,097(10.0)$ \\
\hline \multicolumn{3}{|c|}{ Council of teaching hospitals member } \\
\hline No & $675,249(81.3)$ & $541,556(81.7)$ \\
\hline Yes & $150,440(18.1)$ & $117,176(17.7)$ \\
\hline Not reported/unknown & $5031(0.6)$ & $4134(0.6)$ \\
\hline \multicolumn{3}{|c|}{ Community characteristics (zip code) } \\
\hline \multicolumn{3}{|c|}{ Percent of population unemployed } \\
\hline $0-5 \%$ & $95,725(11.5)$ & $77,264(11.7)$ \\
\hline $6-8 \%$ & $260,369(31.3)$ & $208,787(31.5)$ \\
\hline $9-11 \%$ & $230,791(27.8)$ & $184,317(27.8)$ \\
\hline $12-15 \%$ & $155,421(18.7)$ & $123,043(18.6)$ \\
\hline$\geq 16 \%$ & $88,414(10.6)$ & $69,455(10.5)$ \\
\hline \multicolumn{3}{|c|}{ Percent of population, black or African American } \\
\hline $0-1 \%$ & $183,904(22.1)$ & $148,852(22.5)$ \\
\hline $2-3 \%$ & $145,025(17.5)$ & $116,636(17.6)$ \\
\hline $4-5 \%$ & $87,997(10.6)$ & $70,587(10.6)$ \\
\hline $6-10 \%$ & $124,661(15.0)$ & $99,529(15.0)$ \\
\hline $11-20 \%$ & $114,407(13.8)$ & $90,978(13.7)$ \\
\hline $21-40 \%$ & $90,602(10.9)$ & $71,360(10.8)$ \\
\hline$\geq 41 \%$ & $84,124(10.1)$ & $64,924(9.8)$ \\
\hline \multicolumn{3}{|c|}{ Percent of population, Hispanic } \\
\hline $0-1 \%$ & $90,385(10.9)$ & $72,473(10.9)$ \\
\hline $2-3 \%$ & $153,434(18.5)$ & $123,561(18.6)$ \\
\hline $4-5 \%$ & $106,717(12.9)$ & $85,911(13.0)$ \\
\hline $6-10 \%$ & $156,509(18.8)$ & $124,846(18.8)$ \\
\hline $11-20 \%$ & $136,061(16.4)$ & $108,231(16.3)$ \\
\hline $21-40 \%$ & $101,608(12.2)$ & $803,78(12.1)$ \\
\hline$\geq 41 \%$ & $86,006(10.4)$ & $67,466(10.2)$ \\
\hline \multicolumn{3}{|c|}{ Percent of population, high school degree or higher } \\
\hline $0-20 \%$ & $105,685(12.7)$ & $83,642(12.6)$ \\
\hline $21-25 \%$ & $129,294(15.6)$ & $102,210(15.4)$ \\
\hline $26-28 \%$ & $103,013(12.4)$ & $82,093(12.4)$ \\
\hline $29-33 \%$ & $177,288(21.3)$ & $142,046(21.4)$ \\
\hline $34-38 \%$ & $149,051(17.9)$ & $119,137(18.0)$ \\
\hline $39-45 \%$ & $107,329(12.9)$ & $86,421(13.0)$ \\
\hline$\geq 46 \%$ & $59,060(7.1)$ & $47,317(7.1)$ \\
\hline \multicolumn{3}{|c|}{ Percent of population, below poverty line } \\
\hline $0-7 \%$ & $159,421(19.2)$ & $128,113(19.3)$ \\
\hline $8-10 \%$ & $118,812(14.3)$ & $95,364(14.4)$ \\
\hline $11-15 \%$ & $183,827(22.1)$ & $147,216(22.2)$ \\
\hline $16-18 \%$ & $91,917(11.1)$ & $73,484(11.1)$ \\
\hline
\end{tabular}


Table 1 (continued)

\begin{tabular}{|c|c|c|}
\hline \multirow[t]{3}{*}{ Characteristic } & \multicolumn{2}{|l|}{ Descriptive statistics } \\
\hline & All cases $(n=830,720)$ & $\begin{array}{l}\text { Survived } \\
\text { to discharge } \\
(n=662,866)\end{array}$ \\
\hline & $n(\%)$ & $n(\%)$ \\
\hline $19-25 \%$ & $152,570(18.4)$ & $121,147(18.3)$ \\
\hline$\geq 26 \%$ & $124,173(15.0)$ & $97,542(14.7)$ \\
\hline
\end{tabular}
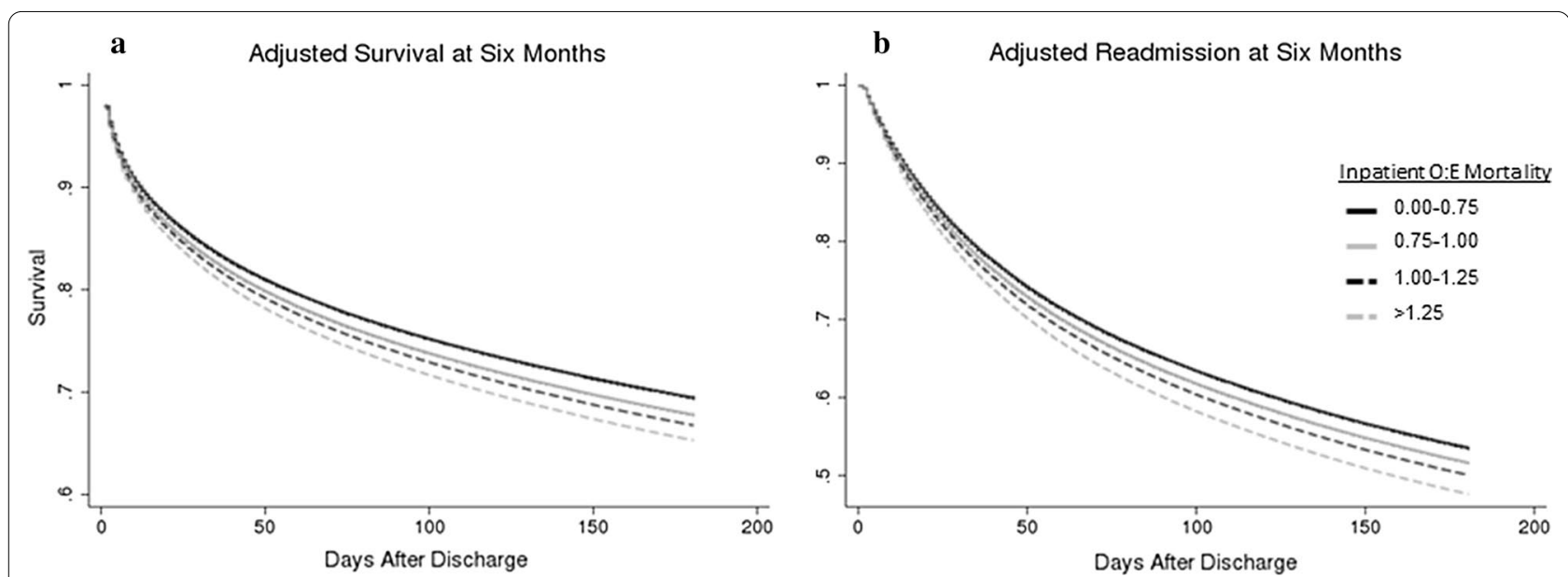

Fig. 3 Cox proportional hazard model curves showing adjusted time-to mortality (a) and time-to-readmission (b) for patients who survive a sepsis hospitalization. Curves are stratified into cohorts defined by the quartile of observed:expected (O:E) in-hospital sepsis mortality aggregated at the level of the hospital. Survival analysis is adjusted for age, race, sex, comorbidities, infection source, organ dysfunction, skilled nursing facility residence prior to admission, community factors (percent Black, percent Hispanic, percent with high school degree or higher, percent below poverty line), ICU services in hospital, teaching hospital

Inpatient quality can be difficult to measure [32, 33], and the factors associated with sepsis quality are myriad $[34,35]$. The Early Management Bundle for Severe Sepsis/Septic Shock (SEP-1) [19] reported by the Centers for Medicare and Medicaid Services is one parameter for ranking hospitals on adherence with a single bundle of very early care, but this measure is not a comprehensive measure of sepsis quality of care and the specific causal relationship between SEP-1 performance and outcomes has been questioned [36-40]. By using an inclusive measure of risk-adjusted inpatient sepsis mortality aggregated at the facility level, we have attempted to capture qualityof-care by its outcome. This study design cannot identify which factors are associated with preventing late mortality or readmissions, but it provides evidence that care factors that affect inpatient outcomes may continue to influence patients after hospital discharge.

What factors might be responsible for the magnitude of the association? Factors associated with post-discharge death could fall into one of four categories: early resuscitation interventions, sub-acute organ support and infection management, de-escalation of therapy, and post-discharge planning and care coordination. Early care interventions, such as timely antibiotics and hemodynamic resuscitation could decrease organ failure and limit the degree of subclinical organ dysfunction persisting at hospital discharge. Immunomodulatory effects of resuscitation may prevent both early organ failure and persistent immune dysfunction [43].

The overall elements of care that are performed after initial resuscitation, including antibiotic use and discontinuation, diuresis, early mobility, delirium management, nutrition, and other factors may also contribute to sepsis outcomes [4, 44-46], but the specific manner in which these practices function as predictors and effect modifiers is not well described. Early mobility, timely extubation, and delirium prevention strategies are welldescribed methods of decreasing mortality and disability from critical illness, and thus are attractive targets to investigate in future studies [47-49]. Finally, discharge 
planning and care coordination may play a significant role in post-discharge follow-up, access to care, medication management, and the transition to community living [50]. Discharge planning, care coordination, and degree of pre-discharge medical recovery also may explain the relationship between inpatient O:E mortality, new skilled nursing discharges, and readmissions, but none of these elements were tested in our analysis. Gadre, et al. recently reported readmissions after nearly $18 \%$ of sepsis discharges, and they were associated with more comorbidities, longer index hospital stays, and residence in skilled nursing facilities [51]. Although conclusive causal relationships have not been established, one might predict that (1) providing high-quality sepsis care that limits deconditioning and chronic organ dysfunction, (2) scheduling discharge timing and managing chronic disease well, and (3) developing strong relationships with primary care providers, community organizations, and post-acute care providers to provide a seamless postacute care transition may effectively limit the need for both skilled nursing and readmissions.

This study has several limitations. First, our use of observational data limits our statistical models to variables commonly recorded in administrative data, allowing for the possibility of unobserved confounders. These available data also led to our use of hospital O:E mortality as a surrogate for hospital quality-likely an incomplete surrogate with some potential for residual confounding and sensitive to differences in coding practices between hospitals. Second, we included only Medicare beneficiaries in these data. While two-thirds of sepsis cases in the U.S. are Medicare beneficiaries, using these cases alone isolates a population over age 65 with reliable payment for healthcare services.

\section{Conclusions}

In conclusion, hospitals with the lowest risk-adjusted sepsis inpatient mortality also have reduced post-discharge mortality. These observations suggest that some factors influencing in-hospital mortality also influence post-discharge outcomes, and some of these factors may be modifiable. Future work should focus on identifying factors associated with post-discharge outcomes and optimizing inpatient and transitional care to improve the likelihood of functional long-term recovery.

\section{Supplementary information}

Supplementary information accompanies this paper at https://doi. org/10.1186/s13054-020-03341-3.

Additional file 1: Figure S1. Distribution of Hospital Sepsis Observed: Expected Mortality Ratio for Included Facilities.
Additional file 2: Table S1. Hospital characteristics by observed to expected (O:E) ratio of in-hospital mortality

Additional file 3: Table S2. Outcomes

\section{Abbreviations}

aHR: Adjusted hazard ratio; aOR: Adjusted odds ratio; CMS: Centers for Medicare and Medicaid Services; ED: Emergency department; ICD-9-CM: International Classification of Diseases, 9th edition, Clinical Modification; IRB: Institutional review board; IQR: Interquartile range; MedPAR: Medicare Provider Analysis and Review; O:E: Observed-to-expected; OR: Odds ratio; RUCC: RuralUrban Continuum Codes; SEP-1: Early Management Bundle for Severe Sepsis/ Septic Shock; STROBE: STrengthening the Reporting of OBservational studies in Epidemiology; 95\% Cl: 95-Percent confidence interval.

\section{Acknowledgements}

This study was presented in abstract form at the Society for Academic Emergency Medicine Annual Meeting in Las Vegas, Nevada on May 16, 2019.

\section{Authors' contributions}

NMM, AMZ, DFG, DGB, and BJC conceived the study, designed the analysis, and interpreted the results. BJC secured funding for the study. NMM and AMZ drafted the manuscript and created figures and tables, and DFG, DGG, and $B G C$ revised the manuscript for important intellectual content. AMZ conducted the statistical analysis, and all authors interpreted the statistical analysis. All authors read and approved the final manuscript.

\section{Funding}

The data source for this study was funded by the Agency for Healthcare Research and Quality (R01HS023614-01) and the NHLBI (R01HL141841-01). Dr. Carr spends a portion of his time as the director of the Emergency Care Coordination Center in the Office of the Assistant Secretary for Preparedness and Response. Dr. Mohr additionally received support from the Agency for Healthcare Research and Quality (K08HS025753). These contents are solely the responsibility of the authors and do not necessarily reflect the views of the Agency for Healthcare Research and Quality, the National Institutes of Health, or the U.S. Department of Health and Human Services.

\section{Availability of data and materials}

Because of confidentiality restrictions with the data sets used, the data set used for this analysis is not available for sharing.

\section{Code availability \\ Not Applicable.}

\section{Ethics approval and consent to participate}

Thomas Jefferson University Institutional Review Board.

\section{Consent for publication}

Not applicable.

\section{Competing interests}

No conflicts of interest were declared.

\section{Author details}

1 Department of Emergency Medicine, University of lowa Carver College of Medicine, 200 Hawkins Drive, 1008 RCP, lowa City, IA 52242, USA. ${ }^{2}$ Division of Critical Care, Department of Anesthesia, University of lowa Carver College of Medicine, lowa City, IA, USA. ${ }^{3}$ Department of Emergency Medicine, Thomas Jefferson University, Philadelphia, PA, USA. ${ }^{4}$ Mount Sinai University, New York, NY, USA.

Received: 9 June 2020 Accepted: 11 October 2020 Published online: 27 October 2020 


\section{References}

1. Rhee C, Dantes R, Epstein L, Murphy DJ, Seymour CW, Iwashyna TJ, et al. Incidence and trends of sepsis in US hospitals using clinical vs claims data, 2009-2014. JAMA. 2017;318(13):1241-9.

2. Buchman TG, Simpson SQ, Sciarretta KL, Finne KP, Sowers N, Collier M, et al. Sepsis among medicare beneficiaries: 1. The burdens of sepsis, 2012-2018. Crit Care Med. 2020;48(3):276-88.

3. Rivers E, Nguyen B, Havstad S, Ressler J, Muzzin A, Knoblich B, et al. Early goal-directed therapy in the treatment of severe sepsis and septic shock. N Engl J Med. 2001;345(19):1368-77

4. Kumar A, Roberts D, Wood KE, Light B, Parrillo JE, Sharma S, et al. Duration of hypotension before initiation of effective antimicrobial therapy is the critical determinant of survival in human septic shock. Crit Care Med. 2006;34(6):1589-96.

5. Hatfield KM, Dantes RB, Baggs J, Sapiano MRP, Fiore AE, Jernigan JA, et al. Assessing variability in hospital-level mortality among U.S. medicare beneficiaries with hospitalizations for severe sepsis and septic shock. Crit Care Med. 2018;46(11):1753-60.

6. Brück E, Schandl A, Bottai M, Sackey P. The impact of sepsis, delirium, and psychological distress on self-rated cognitive function in ICU survivors - a prospective cohort study. J Intensive Care. 2018;6(1):2.

7. Davydow DS, Hough CL, Langa KM, Iwashyna TJ. Symptoms of depression in survivors of severe sepsis: a prospective cohort study of older Americans. Am J Geriatr Psych. 2013;21(9):887-97.

8. Iwashyna TJ, Ely EW, Smith DM, Langa KM. Long-term cognitive impairment and functional disability among survivors of severe sepsis. JAMA. 2010;304(16):1787-94.

9. Winters BD, Eberlein M, Leung J, Needham DM, Pronovost PJ, Sevransky JE. Long-term mortality and quality of life in sepsis: a systematic review. Crit Care Med. 2010;38(5):1276-83.

10. Yende S, Austin S, Rhodes A, Finfer S, Opal S, Thompson T, et al. Longterm quality of life among survivors of severe sepsis: analyses of two international trials. Crit Care Med. 2016;44(8):1461-7.

11. Shankar-Hari M, Saha R, Wilson J, Prescott HC, Harrison D, Rowan $\mathrm{K}$, et al. Rate and risk factors for rehospitalisation in sepsis survivors: systematic review and meta-analysis. Intensive Care Med. 2020;46(4):619-36.

12. Prescott HC, Osterholzer JJ, Langa KM, Angus DC, Iwashyna TJ. Late mortality after sepsis: propensity matched cohort study. BMJ. 2016;353:i2375

13. Ou SM, Chu H, Chao PW, Lee YJ, Kuo SC, Chen TJ, et al. Long-term mortality and major adverse cardiovascular events in sepsis survivors. A nationwide population-based study. Am J Respir Crit Care Med. 2016;194(2):209-17.

14. Czaja AS, Zimmerman JJ, Nathens AB. Readmission and late mortality after pediatric severe sepsis. Pediatrics. 2009;123(3):849-57.

15. Shankar-Hari M, Harrison DA, Ferrando-Vivas P, Rubenfeld GD, Rowan K. Risk factors at index hospitalization associated with longer-term mortality in adult sepsis survivors. JAMA Netw Open. 2019;2(5):e194900-e.

16. Courtright KR, Jordan L, Murtaugh CM, Barron Y, Deb P, Moore S, et al. Risk factors for long-term mortality and patterns of end-of-life care among medicare sepsis survivors discharged to home health care. JAMA Netw Open. 2020;3(2):e200038.

17. Wang HE, Donnelly JP, Shapiro NI, Hohmann SF, Levitan EB. Hospital variations in severe sepsis mortality. Am J Med Qual. 2014;30(4):328-36.

18. Deb P, Murtaugh CM, Bowles KH, Mikkelsen ME, Khajavi HN, Moore S, et al. Does early follow-up improve the outcomes of sepsis survivors discharged to home health care? Med Care. 2019;57(8):633-40.

19. Severe Sepsis and Septic Shock, Sepsis Bundle Project (SEP-1), National Hospital Inpatient Quality Measures. Specifications Manual for National Hospital Inpatient Quality Measures. 5.3. Baltimore, Maryland: Center for Medicare \& Medicaid Services;2017. p. 1-60.

20. von Elm E, Altman DG, Egger M, Pocock SJ, Gøtzsche PC, Vandenbroucke JP. The strengthening the reporting of observational studies in epidemiology (STROBE) statement: guidelines for reporting observational studies. The Lancet. 2007:370(9596):1453-7.

21. Lagu T, Rothberg MB, Shieh MS, Pekow PS, Steingrub JS, Lindenauer PK. Hospitalizations, costs, and outcomes of severe sepsis in the United States 2003 to 2007. Crit Care Med. 2012;40(3):754-61.
22. Dombrovskiy VY, Martin AA, Sunderram J, Paz HL. Facing the challenge: decreasing case fatality rates in severe sepsis despite increasing hospitalizations. Crit Care Med. 2005;33(11):2555-62

23. Dombrovskiy VY, Martin AA, Sunderram J, Paz HL. Rapid increase in hospitalization and mortality rates for severe sepsis in the United States: a trend analysis from 1993 to 2003. Crit Care Med. 2007;35(5):1244-50.

24. Parker T. Rural-urban continuum codes. Washington, DC: Economic Research Service, US Department of Agriculture; 2019. https://www.ers. usda.gov/data-products/rural-urban-continuum-codes/documentation/.

25. Elixhauser A, Steiner C, Harris DR, Coffey RM. Comorbidity measures for use with administrative data. Med Care. 1998;36(1):8-27.

26. Schwarzkopf D, Fleischmann-Struzek C, Rüddel H, Reinhart K, ThomasRüddel DO. A risk-model for hospital mortality among patients with severe sepsis or septic shock based on German national administrative claims data. PLoS ONE. 2018;13(3):e0194371.

27. Quartin AA, Schein RM, Kett DH, Peduzzi PN. Magnitude and duration of the effect of sepsis on survival. Department of Veterans Affairs Systemic Sepsis Cooperative Studies Group. JAMA. 1997;277(13):1058-63.

28. Stortz JA, Murphy TJ, Raymond SL, Mira JC, Ungaro R, Dirain ML, et al. Evidence for persistent immune suppression in patients who develop chronic critical illness after sepsis. Shock. 2018;49(3):249-58.

29. Yende S, D'Angelo G, Kellum JA, Weissfeld L, Fine J, Welch RD, et al. Inflammatory markers at hospital discharge predict subsequent mortality after pneumonia and sepsis. Am J Respir Crit Care Med. 2008;177(11):1242-7.

30. Kaynar AM, Yende S, Zhu L, Frederick DR, Chambers R, Burton CL, et al. Effects of intra-abdominal sepsis on atherosclerosis in mice. Crit Care. 2014;18(5):469.

31. Carson WF, Cavassani KA, Dou Y, Kunkel SL. Epigenetic regulation of immune cell functions during post-septic immunosuppression. Epigenetics. 2011;6(3):273-83.

32. Saver BG, Martin SA, Adler RN, Candib LM, Deligiannidis KE, Golding J, et al. Care that matters: quality measurement and health care. PLoS Med. 2015;12(11):e1001902-e.

33. Hanefeld J, Powell-Jackson T, Balabanova D. Understanding and measuring quality of care: dealing with complexity. Bull World Health Organ. 2017:95:368-74.

34. Walkey AJ, Lindenauer PK. Keeping it simple in sepsis measures. J Hosp Med. 2017;12(12):1019-20.

35. Kramer RD, Cooke CR, Liu V, Miller RR, Iwashyna TJ. Variation in the contents of sepsis bundles and quality measures. A systematic review. Ann Am Thorac Soc. 2015;12(11):1676-84.

36. Barbash IJ, Davis B, Kahn JM. National performance on the medicare SEP-1 sepsis quality measure. Crit Care Med. 2019;47(8):1026-32.

37. Rhee C, Filbin MR, Massaro AF, Bulger AL, McEachern D, Tobin KA, et al. Compliance with the national SEP-1 quality measure and association with sepsis outcomes: a multicenter retrospective cohort study. Crit Care Med. 2018;46(10):1585-91.

38. Kahn JM, Davis BS, Yabes JG, Chang C-CH, Chong DH, Hershey TB, et al. Association between state-mandated protocolized sepsis care and inhospital mortality among adults with sepsis. JAMA. 2019;322(3):240-50.

39. Motzkus CA, Lilly CM. Accountability for sepsis treatment: the SEP-1 core measure. Chest. 2017;151(5):955-7.

40. Gesenway D. SEP-1: does it improve sepsis care? 2018 Mar. https://www. todayshospitalist.com/sep-1-improve-sepsis-care/.

41. Levy MM, Gesten FC, Phillips GS, Terry KM, Seymour CW, Prescott HC, et al Mortality changes associated with mandated public reporting for sepsis: the results of the New York State initiative. Am J Respir Crit Care Med. 2018;198(11):1406-12.

42. Levy MM, Rhodes A, Phillips GS, Townsend SR, Schorr CA, Beale R, et al. Surviving sepsis campaign: association between performance metrics and outcomes in a 75-year study. Intensive Care Med. 2014:40(11):1623-33.

43. Rivers EP, Kruse JA, Jacobsen G, Shah K, Loomba M, Otero R, et al. The influence of early hemodynamic optimization on biomarker patterns of severe sepsis and septic shock. Crit Care Med. 2007;35(9):2016-24.

44. Shen $Y$, Zhang $W$, Shen $Y$. Early diuretic use and mortality in critically ill patients with vasopressor support: a propensity score-matching analysis. Crit Care. 2019:23(1):9.

45. Hickmann CE, Castanares-Zapatero D, Deldicque L, Van den Bergh P, Caty $G$, Robert A, et al. Impact of very early physical therapy during septic 
shock on skeletal muscle: a randomized controlled trial. Crit Care Med. 2018;46(9):1436-43.

46. Stephens RJ, Ablordeppey E, Drewry AM, Palmer C, Wessman BT, Mohr $\mathrm{NM}$, et al. Analgosedation practices and the impact of sedation depth on clinical outcomes among patients requiring mechanical ventilation in the ed: a cohort study. Chest. 2017;152(5):963-71.

47. Barnes-Daly MA, Phillips G, Ely EW. Improving hospital survival and reducing brain dysfunction at seven California community hospitals: implementing PAD guidelines via the ABCDEF bundle in 6,064 patients. Crit Care Med. 2017:45(2):171-8

48. Pun BT, Balas MC, Barnes-Daly MA, Thompson JL, Aldrich JM, Barr J, et al. Caring for critically III patients with the ABCDEF bundle: results of the ICU liberation collaborative in over 15,000 adults. Crit Care Med. 2019;47(1):3-14.
49. Marra A, Ely EW, Pandharipande PP, Patel MB. The ABCDEF bundle in critical care. Crit Care Clin. 2017;33(2):225-43.

50. Peikes D, Chen A, Schore J, Brown R. Effects of care coordination on hospitalization, quality of care, and health care expenditures among medicare beneficiaries: 15 randomized trials. JAMA. 2009;301(6):603-18

51. Gadre SK, Shah M, Mireles-Cabodevila E, Patel B, Duggal A. Epidemiology and predictors of 30-day readmission in patients with sepsis. Chest. 2019;155(3):483-90.

\section{Publisher's Note}

Springer Nature remains neutral with regard to jurisdictional claims in published maps and institutional affiliations.
Ready to submit your research? Choose BMC and benefit from:

- fast, convenient online submission

- thorough peer review by experienced researchers in your field

- rapid publication on acceptance

- support for research data, including large and complex data types

- gold Open Access which fosters wider collaboration and increased citations

- maximum visibility for your research: over $100 \mathrm{M}$ website views per year

At BMC, research is always in progress.

Learn more biomedcentral.com/submissions 